\title{
Modified Use of Team-Based Learning to Teach Nursing Documentation
}

\author{
Fatemeh Ebrahimpour ${ }^{1}$, Ferdos Pelarak ${ }^{2}$
}

\author{
${ }^{1}$ M.Sc. of Nursing Education, Faculty of Nursing \& Midwifery, Qazvin University of Medical Sciences, Qazvin, \\ Iran \\ ${ }^{2}$ M.Sc. of Nursing Education, Faculty Member of Nursing \& Midwifery, Dezful University of Medical Sciences, \\ Dezful, Iran
}

\section{Type of article: Original}

\begin{abstract}
Introduction: Nursing documentation is one of the main parts of clinical documentation. Poor knowledge of nurses in documentation methods could bring about problems for patients and nurses. It is very important to promote nurses' knowledge and skills in this regard through effective teaching methods. The aim of this study was to use Team-Based Learning (TBL) to teach nursing documentation for nurses.

Methods: TBL was implemented for 20 nurses participating in a nursing documentation workshop in Qazvin, Iran, in 2015. TBL consists of three main stages. The first stage is the learners' reading about the subject matter. The second stage is measuring the learners' knowledge about the subject matter they have studied using the Individual Readiness Assurance Test (IRAT). In the third stage, more profound learning is achieved by forming small groups and performing teamwork. Finally, participants' views and experiences about TBL were investigated using observations and interviews.

Results: The results showed that TBL method increases transfer of information and improves intrapersonal relationships and collaboration. All nurses were satisfied with the educational content and the TBL method. The strong points of this workshop included obtaining the viewpoints of the nurses, step-by-step integration of the contents of teamwork, consultation and active participation of all participants, high learning motivation, and creating a sense of competition. The nurses viewed TBL as a useful method to improve their reporting skills.

Conclusion: Using new teaching methods based on teamwork could bring about achievements, including improvement of intrapersonal relationships and teamwork, which are requisites of nursing in addition to facilitating the learning of educational content. It is suggested that the TBL method be used to improve teaching and to increase nurses' skills and knowledge.
\end{abstract}

Keywords: nursing report, team-based learning, education, nursing record, documentation

\section{Introduction}

Nursing documentation is one of the main parts of clinical documentation $(1,2)$. Nurses spend about one-third of their shift work time on writing nursing reports (3). In other words, reporting is an important part of nursing performance that plays an important role in the quality of presenting nursing care and facilitating the relationship between nurses and other members of healthcare team; in addition, their reports are the only means of advocating for nurses in legal and judicial proceedings (4-6). Obviously, the importance and applications of nursing reports becomes significant when these reports are recorded accurately based on standards. Recording an erroneous and incomplete report results in dissociation in patient care, and it would decrease patients' satisfaction and damage their safety by increasing expenditures and the duration of hospitalization, delays in diagnosis and treatment of their illnesses, and the prevalence of accidents or clinical mistakes (7). In Iran, nursing reports traditionally have been recorded (8), and some studies have shown that nursing reports are unsatisfactory, in such a way that results of investigating cases based on observation sheet showed that generally $17.09 \%$ of reports are recorded properly, and

\section{Corresponding author:}

Fatemeh Ebrahimpour, Faculty of Nursing \& Midwifery, Qazvin University of Medical Sciences, Shahid Bahonar Blvd., Qazvin, Iran. Tel: +98.2833237268, Fax:+98.2833237268, E-mail: Fa2892@Yahoo.com

Received: August 07, 2015, Accepted: December 20, 2015, Published: January 2016

iThenticate screening: November 16, 2015, English editing: January 03, 2016, Quality control: January 05, 2016

(C) 2015 The Authors. This is an open access article under the terms of the Creative Commons Attribution-NonCommercialNoDerivs License, which permits use and distribution in any medium, provided the original work is properly cited, the use is non-commercial and no modifications or adaptations are made. 
$81.35 \%$ are recorded incompletely, with $48 \%$ of the reports omitting some of the necessary information (9). One of the reasons of inaccurate reporting is insufficient knowledge of nurses about principles of reporting and documentation in patients' records (5). The results of Ghazanfari et al.'s study of 226 nurses working in hospitals indicated that $46.5 \%$ of nurses have a medium knowledge of reporting principles. In addition, this study pointed to the relationship between participating reporting courses and high level of knowledge in nurses about this matter (10). Therefore, holding training workshops periodically could assist in improving nursing reports (11). Choosing proper education and teaching methods is very important when implementing an educational program (12). Within the last few decades, using new teaching methods is especially considered, among which Team-Based Learning (TBL) could be mentioned $(13,14)$. In 1970, Michaelsen designed TBL with the aim of increasing the quality of learning through employing problem-solving skills in an active and participatory learning environment (15). In other words, learners could achieve a higher level of cognitive learning by utilizing their personal knowledge in consulting with small groups $(16,17)$. Some studies have emphasized the positive effect of TBL compared to the lecture method in medical education (18-20). The aim of this study was to use Team-Based Learning (TBL) to teach nursing documentation for nurses.

\section{Material and Methods}

\subsection{Setting}

TBL was implemented to teach 20 nurses participating in a three-hour workshop on nursing documentation principles in a general hospital in Ghazvin, Iran, in 2015. A step of doing this was based on the TBL method. However, with regard to the conditions of workshop and the subject matter, TBL was modified a little. In general, our training program was a combination of the lecture method and the modified TBL method.

\subsection{Steps of Team-Based Learning}

According to Michaelsen's plan, there are three main steps in implementing TBL. The first step is the necessity for reading about the subject matter and the readiness of learners. The second step is measuring learners' knowledge about the subject matter studied in the first step using individual testing. In addition, in this step, group readiness testing and pervasive discussion with the teacher take place. In the third step, which is a higher level of learning, more profound learning is achieved by forming small groups and doing group assignments $(21,22)$.

\subsubsection{Step 1: preparation (pre-workshop)}

1) Educational content: Educational content including basic concepts of reporting, objectives, importance and applications of reporting, features of a good report, different types of reporting methods along with standard principles of nursing report were prepared from authentic and international textbooks on teaching nursing principles and skills $(33,24)$, in the form of slideshows.

2) Individual Study: At this stage of the TBL method, learners should have read books, journals, and articles based on subjects selected by the teacher to participate in the TBL program with proper knowledge. Since the concepts related to the workshop are previously taught in academic B.S. nursing courses and nurses record their daily clinical activities, they do not have any pre-reading and participated workshop with their previous knowledge.

\subsubsection{Step 2: Readiness Assurance (In-Workshop)}

1) Test: When the workshop was started, sufficient explanations were presented about holding the workshop in TBL form and tasks of participants during workshop after introducing participants and statement of educational objectives. Then, using Individual Readiness Assurance Test (IRAT), nurses answered 10 multiple-choice questions related to nursing documentation, individually and based on their personal knowledge within 10 minutes. Questionnaires were scored, and each right answer received one score. Then, to conduct Group Readiness Assurance Test (GRAT), participants were divided into four groups and answered the same multiple-choice questions using group knowledge and the test was scored as before. When the tests were finished, scores of IRAT and GRAT were written on the white board.

2) Theoretical Teaching: In the workshop, teachers taught the contents related to primary concepts of reporting, objectives, the importance and applications of reporting, and features of a good report in the form of lecture and question-answer using slide shows within 30 minutes.

3) Teamwork: To assess participants' learning of the contents presented, another group assignment was conducted in such a way that a sample of nursing documentation written in the records was taken to each group to evaluate within 15 to 20 minutes, considering six standards for a good report. These standards included actuality, accuracy, being a dynamic organization, completeness, and conciseness and then to modify the report based on these criteria. Then, representatives of each group presented their evaluation 
within 5 to 10 minutes, stated their reasons for modifying the nursing report, and discussed it with other participants (team appeals). For each modified criterion, one score was considered and group scoring was notified at the end.

4) Theoretical Teaching: Other topics related to reporting methods and standard principles of nursing report were taught within 30 minutes as before.

2.2.3. Step 3: Application of Course Concepts

1) Group Assignment: In this step, a group assignment was conducted with the aim of more effective learning of presented contents among nurses. To do so, four clinical scenarios were provided considering the conducted studies and clinical experiences of the teacher, each one of which consisted of clinical history of a patient along with medication and care measures and special clinical conditions (Box 1). After receiving their scenarios, each group began writing the nursing documentation in forms within 30 minutes. The teacher also answered their questions in a group and directed group comments and discussions as well. To evaluate the nurses' group assignment, peer evaluation was employed in such a way that when time finished, the nursing documentation provided by each group was evaluated and scored in other three groups according to checklist.

2) End of Workshop: At the end of workshop, the top groups were selected based on the total score. In addition, important notes of reporting were mentioned and participants' views and experiences about team learning were investigated using observations of the researchers and interviews.

Box 1. A sample of nursing report scenario

You are a nurse and work in hospital emergency room. You care for a patient with following characteristics. Please write a nursing report for this patient and use correct principles of nursing documentation for it. The time was 09:30 when the paramedics brought a 68-year-old man with chest pain and a history of diabetes, hypertension. His ECG showed ST segment elevation. Vital signs were blood pressure 105/65 $\mathrm{mm} \mathrm{Hg}$ (hypotensive), Pulse of 58 (bradycardic) weak and irregular, Respiration rate 18 (tachypnea), SpO2: 87\% (hypoxemic). He had acute pain and was anxiety. In route, a nasal cannula was placed with oxygen at 4 Liter. A cardiac monitor was placed, and the rhythm was sinus rhythm with ST elevation of greater than $0.1 \mathrm{~mm}$. Nonenteric-coated aspirin $325 \mathrm{mg}$ was given to his to chew along with sublingual nitroglycerin $0.4 \mathrm{mg}$ and morphine $2 \mathrm{mg}$ IV. After 20 minutes his pain realized. Lab test of CBC, BS, Troponin I and CK-MB was requested. He stayed in the emergency room for another 4 hours for monitoring prior to admission to the cardiac unit. His vital singe controlled per 1 hour. His should completed bed rest and allowed diabetic and low salt-fat diet.

\section{Results}

The ages of the participating nurses ranged from 20 to 35. Their average job history was four years. They were working at emergency, ICU, and surgical wards. Eighty percent of nurses were females, and $60 \%$ of them were married. Two participants had participated in a nursing documentation retraining course before. In our observations, it was determined that as an organized teamwork, TBL could increase transfer of learning, improve intrapersonal relationship, and increase learning motivation and group partnership. In the survey conducted, 100\% of participants were satisfied with the content of workshop and TBL method. All participating nurses stated that holding nursing documentation workshop is necessary and useful. In addition, 74\% of participants believed that nurses do not have sufficient motivation to attend training programs because of various responsibilities, fatigue due to heavy workload, and night shifts or low quality of workshops held. All participants stated that workshops should be useful, functional, and attractive. In this regard, 92\% of participants evaluated the integration of lecture and TBL method as a useful and creative method to improve their reporting. Ninety percent of the participants were satisfied with systematic integration of presenting theoretical contents and teamwork related to that. Nurses stated factors including consulting (52\%), and active participation (75\%), high learning motivation (85\%) and creating the sense of competition and vitality (55\%) as the strong points of training program.

\section{Discussion}

The turning point of our educational strategy is employing modified TBL in holding nursing report workshop. The experience obtained by participants and authors shows successful application of TBL in teaching and learning nursing report principles. All nurses participating in our teaching program were satisfied with TBL method. TBL is an active learning method in the form of teamwork and it is welcomed in different fields including medicine and nursing as an effective training tool (25). Results of the study by Shellenberger showed that TBL is an effective 
method to learn clinical skills according to the students of medicine (26). Another study states that TBL assists in learning concepts and primary knowledge for clinical clerkship and it improves performance of the students of medicine (27). TBL is a useful and common method in nursing education that creates person-to-person learning opportunity for nurses by increasing intrapersonal interactions and teamwork (28). Results of Cheng et al. showed that TBL is an effective teaching method in curriculum of B.S. nursing students and improves their learning behavior and academic performance, significantly (29). In their study, Considine et al. investigated the effect of the TBL method on improving nurses' capabilities in examining and managing patients with hip joint damage. According to nurses, this teaching method accompanies positive individual and team experience along with high learning quality and prepares them for better performance in the team (30). In another study, it was stated that nurses have experienced deep and satisfactory learning and TBL could be useful in reinforcing critical thinking, teamwork skills and communicative skill that are requisites of making decisions and clinical nursing cares (31). Roh stated that factors including pre-assignment, course content, peer evaluation and team activity are effective in nursing students' satisfaction of TBL (32). Based on the results of studies, it should be noted that, in addition to increasing interaction between professors and students and facilitating students' learning, TBL could be effective in other educational programs, including in-service training of nurses and increasing their knowledge.

\section{Conclusions}

The results of this study showed that using TBL could increase learning transfer and motivation and it could improve team participation of nurses in teaching reporting principles. Employing new teaching methods, which are based on teamwork, could bring about other achievements, including improvement of intrapersonal skills, team participation and critical thinking, and problem-solving skills that are requisites of a nursing career, along with facilitating educational content learning. Therefore, using TBL could be a proper method to achieve educational objectives in nurses' training. Thus, it is suggested to utilize the TBL method in teaching and increasing nursing knowledge and skills more than before.

\section{Acknowledgments:}

We thank the nurses who participated in this study for their cooperation, and we also thank the reviewers of Electronic Physician Journal for their constructive comments that enhanced the quality of the paper.

\section{Conflict of Interest:}

There is no conflict of interest to be declared.

\section{Authors' contributions:}

Both authors contributed to this project and article equally. All authors read and approved the final manuscript.

\section{References}

1) Mahler C, Ammenwerth E, Wagner A, Tautz A, Happek T, Hoppe B, et al. Effects of a computer-based nursing documentation system on the quality of nursing documentation. J Med Syst. 2007; 31(4): 274-82. PMID: 17685151.

2) Dehghan M, Dehghan D, SheikhraboriA, Sadeghi M, Jalalian M. Quality improvement in clinical documentation: does clinical governance work? J Multidiscip Healthc. 2013; 6: 441-50. doi: 10.2147/JMDH.S53252., PMID: 24324339, PMCID: PMC3855011.

3) Clancy TR, Delaney CW. The benefits of standardized nursing languages in complex adaptive systems such as hospitals. J Nurs Adm. 2006; 36(9): 426-34. PMID: 16969254.

4) Wang N, Hailey D, Yu P. Quality of nursing documentation and approaches to its evaluation: a mixedmethod systematic review. J Adv Nurs. 2011; 67(9): 1858-75. doi: 10.1111/j.1365-2648.2011.05634.x, PMID: 21466578.

5) Abbaszadeh A, Sabeghi H, Borhani F, Heydari A. A comparative study on effect of E-learning and instructor-led methods on nurses documentation competency. Iran J Nurs Midwifery Res. 2011; 16(3): 23543. PMID: 22224113.

6) Jasemi M, Zamanzadeh V, Rahmani A, Mohajjel A, Alsadathoseini F. Knowledge and practice of Tabriz teaching hospitals nurses regarding nursing documentation. Thrita J Med Sci. 2013; 1(4): 133-8. doi:10.5812/thita.8023.

7) Instefjord MH, Aasekjær K, Espehaug B, Graverholt B. Assessment of quality in psychiatric nursing documentation - A clinical audit. BMC Nurs. 2014; 13(32). doi: 10.1186/1472-6955-13-32, PMID: 25349532 . 
8) Nasiriani Kh, Dehghani H, Akbari Roknabadi M. Nursing documentation requirements in coronary care unit. Iran J Crit Care Nurs. 2014; 6(s): 132-41.

9) Hanifi N, Mohamadi E. Survey of causes of faculty nursing documentation. hayat. 2014; 10(2): 39-46.

10) Ghazanfari Z, Sheykhpour-khani M, Haghdoost A. Nurse's knowledge and practice of the principles of nursing documentation at hospitals of Kerman University of Medical Sciences. IJN. 2009; 22(59): 15-22.

11) Okaisu EM, Kalikwani F, WanyanaG, Coetzee M. Improving the quality of nursing documentation: An action research project. Curationis. 2014; 38(1). doi: 10.4102/curationis.v37i1.125.

12) Pourghaznein T, Sabeghi H, Shariatinejad K. Effects of E-learning, lectures, and role playing on nursing students knowledge acquisition, retention and satisfaction. Med J Islam Repub Iran. 2015; 29(162). PMCID: PMC4431360.

13) Nasiri Oskouei N, Saemian F. Analyzing and comparing the effects of two teaching methods, studentcentered versus teacher-centered, on the learning of biostatistics at SBMU. JPS. 2012; 3(4): 17-24.

14) Khoshnevisasl P, Sadeghzadeh M, Mazloomzadeh S, Hashemi Feshareki R, Ahmadiafshar A. Comparison of Problem-Based Learning with lecture-based learning. Iran Red Crescent Med J. 2014;16(5):e5186 .doi: 10.5812/ircmj.5186, PMCID: PMC4082522.

15) Beatty SJ, Kelley KA, Metzger AH, Bellebaum KL, McAuley JM. Instructional design and assessment Team-Based Learning in therapeutics workshop tessions. AJPE. 2009; 73(6). doi: 10.5688/aj7306100, PMID: 19885069, PMCID: PMC2769522

16) Persky AM, Henry T, Campbell A. An exploratory analysis of personality, attitudes, and study skills on the learning curve within a Team-Based Learning environment. Am J Pharm Educ. 2015; 79(2). doi: 10.5688/ajpe79220, PMCID: PMC4386741.

17) Miller CJ, Falcone JC, Metz MJ. A comparison of Team-Based Learning formats: can we minimize stress while maximizing results? World J of Educ. 2015; 5(4) .doi: 10.5430/wje.v5n4p1.

18) Jafari Z. Comparison of rehabilitation students learning in neurology through lecture with Team-Based Learning (TBL). IJME. 2013; 13(5): 448-56.

19) Keshani F, Alikhasi M, Azmoodeh F. Comparison of the effects of lecture and Team Based Learning (TBL) on oral and maxillofacial pathology learning in dental students. JQUMS. 2015; 19(3): 60-3.

20) Vasan NS, DeFouwDO, Holland BK. Modified use of Team-Based Learning for effective delivery of medical gross anatomy and embryology. Anat Sci Educ. 2008; 1(1): 3-9. PMID: 19177372.

21) Zgheib NK, Simaan JA, Sabra R. Using Team-Based Learning to teach pharmacology to secondyear medical students improves student performance. Med Teach. 2010; 32(2): 130-5. doi: 10.3109/01421590903548521, PMID: 19177372.

22) Mennenga HA, Smyer T. A model for easily incorporating Team-Based Learning into nursing education. Int J Nurs Educ Scholarsh. 2010; 7(1). doi: 10.2202/1548-923X.1924, PMID: 19177372.

23) Taylor C, lillis C, lynn P. Fundamental of nursing: The art and science of person-centered nursing care, 8 th ed,Wolters Kluwer; 2015.

24) lynn P.Taylor's clinical nursing skills. 4 th ed, Wolters Kluwer; 2015.

25) Sisk RJ. Team-Based Bearning: systematic research review. J Nurs Educ. 2011; 50(12): 665-9. PMID: 22007709.

26) Shellenberger S, Seale JP, Harris DL, Johnson JD, Dodrill CL, Velasquez MM. Applying Team-Based Learning in primary care residency programs to increase patient alcoholscreenings and brief interventions. Acad Med. 2009; 84(3): 340-6. doi: 10.1097/ACM.0b013e3181972855, PMID: 19240441.

27) Thomasa PA, Bowena CW. A Controlled trial of Team-Based Learning in an ambulatory medicine clerkship for medical students. Teach Learn Med. 2011; 23(1): 31-6. doi: 10.1080/10401334.2011.536888, PMID: 21240780.

28) Chenga CY, Lioua SR, Tsaib HM, Changa CH. The effects of Team-Based Learning on learning behaviors in the maternal-child nursing course. Nurse Educ Today. 2014; 34(1): 25-30. doi: 10.1016/j.nedt.2013.03.013., PMID: 23618848.

29) Cheng CY, Liou SR, Hsu TH, Pan MY, HC L, Chang CH. Preparing nursing students to be competent for future professional practice: applying the Team-Based Learning-Teaching Strategy. J Prof Nurs. 2013; 30(4): 347-56. doi: 10.1016/j.profnurs.2013.11.005, PMID: 25150421.

30) Considine J, Currey J, Payne R, Williamson S. Participant evaluation of Team-Based Learning using oneoff teams in a hospital setting. Australas Emerg Nurs J. 2014; 17(2): 68-76. doi: 10.1016/j.aenj.2014.03.002, PMID: 24815205. 
31) Currey J, Eustace P, Oldland E, Glanville D, Story I. Developing professional attributes in critical care nurses using Team-Based Learning. Nurse Educ Pract. 2015; 15(3): 232-8. doi: 10.1016/j.nepr.2015.01.011, PMID: 25704795.

32) Roh YS, Lee SJ, Mennenga H. Factors influencing learner satisfaction with team-based learning among nursing students. Nurs Health Sci. 2014; 16(4): 490-7. doi: 10.1111/nhs.12118., PMID: 24636169. 